\section{$008-009$ \\ Noticias $\mathrm{y}$ comentarios}

\section{PH47 - Febrero 2004}

\title{
El arte contemporáneo discute en torno al paisaje urbano
}

Las VI Jornadas de Análisis sobre Dialéctica del Arte Contemporáneo, organizadas por el Colegio Oficial de Doctores y Licenciados en Bellas Artes de Andalucía (COLBBAA) y la Fundación Aparejadores, se desarrollaron durante cuatro miércoles del pasado mes de octubre de 2003. Los debates giraron en torno al título "Paisajes Urbanos". La ciudad, lo social, la plástica tridimensional y el universo de la imagen fueron los debates planteados.

\section{La ciudad, un espacio marco}

Santiago Eraso, director de Arteleku (San Sebastián) y asesor de la UNIA, desarrolló su conferencia "Texto, tejido y confecciones de las redes urbanas" analizando no sólo los movimientos artísticos que se producen en las ciudades actuales, sino también su implicación social y la estrecha relación existente entre algunas formas de arte actual y la hibridación cultural producida por los movimientos migratorios y las nuevas tecnologías de la comunicación.

Defendió la abolición de fronteras y criticó el ensalzamiento de los mitos que hacen que las comunidades se encierren en sí mismas: todos pertenecemos a un contexto, a una comunidad, pero toda identidad es, a su vez, compleja, cambiante y activa.

Hay que creer en la alteridad, en un nuevo humanismo "ser para el otro". Y el espacio de expresión de esta alteridad es una ciudad intercultural y permeable. Proyectó una nueva cartografía desprovista de poder político, en la que la relación entre ciudadanos esté basada en la ética individual y solidaria.

Eraso presentó el desarrollo de un arte apasionado e intersubjetivo, es decir, basado en la relación de las distintas subjetividades, diluyendo la dialéctica individuo / comunidad, espacio público / espacio privado. Para él, las grandes obras de arte público hoy día son proyectos activos, de interrelación con la ciudadanía, no demostraciones de monumentalidad o genialidad individual. En este sentido, Arteleku pretende ser una nueva alternativa a los habituales canales de distribución de la producción artística, dando acogida al des- arrollo de proyectos que muestren esta nueva relación entre el artista y la ciudad.

\section{Lo social, el espacio habitado}

Jesús Palomino, artista sevillano afincado en Rotterdam, fue invitado a las jornadas ya que su obra -dibujos, esculturas, maquetas e instalaciones- tiene como punto de partida los espacios de la ciudad y la metáfora de los comportamientos con respecto a esos espacios. Y en ella aparecen principalmente tres intereses: el drama, como conciencia de la vida, la imaginación, como intuición, y el humor, como expresión de lo humano.

Su arte es procesual, situaciones casuales pueden ser el gatillo de ideas que dan lugar a posibles proyectos: espacios abandonados de la ciudad, lo doméstico, lo privado en lo público. El artista comentó que su arte es social por el simple hecho de ser algo que se muestra a la sociedad y que lo social siempre crea algún tipo de fricción con lo privado. De esta forma, la ley puede dar un marco de igualdad legal, pero no social.

\section{La Plástica tridimensional, conquistar el espacio}

Paula Llul, actual adjunta a dirección de la Fundación NMAC (Montenmedio Arte Contemporáneo), habló principalmente de la evolución que en los últimos tiempos ha tenido el concepto de escultura pública, pasando de un interés puramente esteticista o conmemorativo a una intervención más social o interactiva.

Los regímenes totalitarios de la primera mitad del siglo XX desarrollaron un tipo de escultura monumental, con el fin de ensalzar unos determinados valores y encumbrar unos logros políticos. Actualmente, algunas esculturas públicas atacan directamente estos propósitos ("Biblioteca" de Micha Ullman, monumento a los caídos en Vietnam de Maya Lin, estatua de Franco de Santiago Castillo presentada en el PS1 de Nueva York). A veces, la presión popular puede intervenir en la deposición de obras públicas, como ocurrió con la polémica retirada del "Tilted Arc" de Richard Serra.

Las primeras grandes obras de arte moderno tridimensionales se comienzan a dar en Estados Unidos cuando, en 1959, la ley de porcentaje obliga a invertir una parte de lo gastado en obras públicas, en arte público. Las denominadas agencias comienzan a gestionar proyectos que, en un principio, consisten en grandes esculturas de artistas reconocidos (Picasso, Calder...) colocadas, sin más, frente a los edificios institucionales.

En los años setenta, comienza a realizarse un arte más contextualizado, uniéndose el artista 
al arquitecto y el urbanista. Pero la evolución de estas agencias ha desembocado en un control de estos últimos, en detrimento de la creación de espacios más reflexivos y significativos.

Actualmente, proliferan los proyectos de intervención del espacio, la mayoría efímeros, como los de Alcorcón, "Arte experimental" o "Madrid abierto". En muchas ocasiones las obras escultóricas públicas son escogidas por políticos sin un asesoramiento adecuado o profesional, con lo que se desperdicia la oportunidad (se comentó el caso de Jerez). Otros artistas optan por la intervención individual, como el sevillano Santiago Cirugeda y sus cubas-casa o cubas-columpio.

Llul, finalmente, insistió en que la gestión de la obra de arte pública debe estar siempre contextualizada y consensuada, acompañada de un acercamiento pedagógico al ciudadano y conquistando el espacio desde la libertad.

Segundas pieles en el universo de la imagen La profesora de Filosofía de la Universidad de Sevilla Isabel Ramírez Luque desarrolló en su conferencia un interesante nuevo reto, el de elaborar proyectos estéticos en el entorno urbano con la ayuda de las nuevas tecnologías.
Analizando la evolución de la piel o envoltorio de los edificios a lo largo de la historia, la profesora mostró cómo antes del siglo XX el edificio se cerraba al exterior mediante un muro con su propio orden. En el barroco, el ornamento llegó a su máxima expresión, así como en el modernismo o en algunos edificios de estilo historicista. La Bauhaus supuso un nuevo tipo de piel, más sobria y transparente, con una profusa utilización del vidrio. Loos, defensor de un funcionalismo extremo, llegó a decir "ornamento o delito".

Actualmente se valora, por encima de todo, la interacción con el exterior. La piel del edificio se puede volver permeable, sensible al exterior y reflejo del interior, más relacionada con el paisaje o el medio urbano circundante. Hay una nueva reivindicación de la significación del edificio, de la sensualidad e incluso del simulacro. Para ilustrarnos estos conceptos, Ramírez mostró obras arquitectónicas de Herzog y Nouvel, principalmente.

Rocío Arreguí Pradas

Vocal del COLBBAA

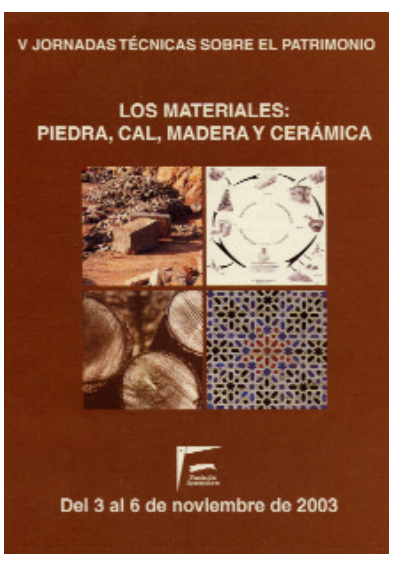

Durante la primera semana de noviembre de 2003 la Fundación Aparejadores organizó las V Jornadas Técnicas sobre el Patrimonio, bajo el título "Materiales básicos: piedra, cal, madera y cerámica".

Desde una aproximación elemental del patrimonio arquitectónico como el resultado de la aplicación de un conjunto de materiales a través de la técnica y de los oficios, con el objeto de definir determinados espacios, el programa de las jornadas toma una consideración de partida: "Cada época ha ido utilizando los materiales que el mercado le ha ido proporcionando con las características propias de cada lugar y del tiempo en el cual es utilizado, de igual forma se ha resuelto el uso de los oficios con el conocimiento y los medios del periodo correspondiente, todo ello muestra y enriquece nuestro amplio patrimonio histórico y artístico".

Desde esta perspectiva, para las $V$ Jornadas se ha considerado apropiado tratar solamente cuatro materiales básicos, muy presentes en el patrimonio arquitectónico andaluz: la piedra, la cal, la madera y la cerámica. Sus características generales, aplicaciones, comportamientos y restauraciones se analizaron por cuatro expertos profesionales en las conferencias programadas.
Las materias fueron expuestas por el ingeniero industrial Manuel Alcalde (piedra), la arquitecta y arquitecta técnica María Dolores Robador (cal), el arquitecto Enrique Morales (madera) y el arquitecto técnico José María Cabeza (cerámica), quien a su vez coordinaba las Jornadas.

Manuel Alcalde prestó especial atención a la variada composición de la piedra y sus diferentes patologías con sus específicas definiciones, así como las medidas para evitar los procesos de degradación. Al mismo tiempo realizó un detenido recorrido por las catedrales de Cádiz, Almería y Sevilla, fruto de sus trabajos de estudio e investigación durante largos años.

Maria Dolores Robador resaltó el resultado que a través de los siglos ha tenido el uso de la cal, citando numerosos ejemplos como la Giralda, la Catedral, iglesias, palacios, conventos, puentes, viviendas, etc., para concluir que es imprescindible seguir utilizando morteros de cal en la trabazón de todos los elementos de una construcción a la hora de rehabilitarla. Además de su utilidad como conglomerante, afirmó, el uso del mortero de cal aporta también sus propiedades de plasticidad, con lo que se constituyen elementos arquitectónicos flexibles que absorben deformaciones, lo que no es posible con materiales mas rígidos como el cemento. 